\title{
On the Improvement of Library Information Services In Higher Education Facilities of Excellent Engineers*
}

\author{
Xu Dai ${ }^{1}$, Zan Liu ${ }^{1}$, Siyuan Chen ${ }^{2}$, Jun $\mathrm{Liu}^{2}$, Zhongning Guo ${ }^{2}$ \\ ${ }^{1}$ Dept. of Library and Information, Guangdong University of Technology, Guangzhou, China \\ ${ }^{2}$ Faculty of Mechanical Electronic Engineering, Guangdong University of Technology, Guangzhou, China \\ Email: lyqing@gdut.edu.cn, imdesign@gdut.edu.cn
}

Received 2012

\begin{abstract}
Relations between the information capabilities of students and the implementation of the project to the education of excellent engineers is analyzed. 62 representative university library websites as well as 189 students in our university were selected for comprehensive study. It is concluded that, the current university library information services have not yet been able to meet the requirements of educational reform, and years of development on digital resources with carrying out in large-scale has not produced desired results at undergraduate education. Three points of reform are proposed on the aspects as follows: (1) on the digital information resources development projects, (2) on the development of the students' information literacy , and (3) on the combination of information literacy education and professional education.
\end{abstract}

Keywords: Excellent Engineer Training Program; E-learning; Information Quality; Library; Information Navigation

\section{Introduction}

"Plan for Educating and Training Outstanding Engineer" (PETOE), is an important project to implement the "National Medium and Long-term Educational Reform and Development Plan" (2010-2020) and the "National Medium and Long-term Talent Development Plan” (2010-2020). The purpose of the project is to train a number of high-level engineering and technical personnel with strong and high innovative motivations and be able to adapt to economic and social developments. Our university comes in the second term of PETOE project, it is crucial that we play our role in the project to provide full support to the reform in all departments.

In recent years, university libraries have been doing a lot of work in digital resource construction to better meet the requirement of teachers' scientific research work and the cultivation of graduate students. But these resources have not played its due role in the undergraduate education. This paper studies the improvement of the college library information service work, to adapt to the requirements of PETOE.

\section{The Relationship between Library Information Services and PETOE}

Pursuant to the 11 common criteria of undergraduate level engineer education of PETOE ${ }^{[1]}$, that criterion No.4 of the "understanding of the professional development status and trends", No.5 of the "understanding of the technical standards of the professional field, policies, laws and regulations in related industries ", No.6 of the "ability of obtaining information and

Funds: 2010 Higher Education Reform Project of Guangdong Province (BKZZ2011022), 2010 experiment teaching Reform Project of Guangdong Province(2010003) capability of professional development”, No.11 of the "international spectator and exchange in a cross-cultural environment, as well as the capacity in competition and cooperation" etc. all requires the services of information and closely associate with e-learning. Whereas, "a good engineering ethics, a strong sense of social responsibility and good humanities literacy" as defined by criterion No.1, and "a strong sense of innovation and capacity in product development and design, and creativity in technological innovation" by criterion No. 8, and " sense of quality, environment, occupational health, safety and service" by criterion No. 9, have much to do with the library information services and e-learning. Therefore, it is concluded that to improve the library information services is an integral part of PETOE.

The major manifestation in the system of curriculum of PETOE is to reflect the ultimate value of the development of students' personal capability ${ }^{[2]}$. Students are the masters of the curriculum. With the participation in course learning, they actively give full play to the studies, take the initiative to acquire knowledge and continuously improve the ability to creatively explore the unknown world. Thus, they will gain comprehensive development in the process of their curriculum studies. To achieve this goal, two important issues must be dealt with in priority: the issue of information access and utilization by students, and the issue of establishment of information resources. These are the two aspects of the same issue, the growth of students' information literacy needs of a gradual process, to effectively facilitate this process for student needs to build up a suitable base of resources. The studies of this thesis is to analyze the existing problems of university library information services and come up with a possible solution of how to build information resources platforms to facilitate undergraduate students for the purpose of improving their quality. 


\section{Problems in Library Information Service in High Education Facilities}

In today's phenomenon of widely used in computers and networks, digital resources have been the main target of use in man's acquisition and utilization of information resources. Students, apart from those who came from the remote and pastoral areas, most of them have already mastered the basic operation of computers and networking. Some of them are even better than the teachers. After they started the life in the university, information retrieval courses are mandatory courses in which students learn the basic principles, methods and skills $[3,4]$.

Under the leadership of the relevant state departments, digital resources construction have been carry out in large-scale such as huge projects like CALI and CADLIS ${ }^{[5-9]}$. Colleges and universities with their own academic strengths have been undertaking a lot of work in primary and secondary literature database construction ${ }^{[10-16]}$. Most colleges and universities directly under the Ministry of Education have built database with characteristics of their scientific subject. These database systems have comprehensive collection of their own scientific area or topics, and have been providing strong support to the studies of the subject matter with sufficient depth and breadth coverage.

However, the authors found in daily work that the majority of undergraduate students in the use of library facilities of digital resources are limited to bibliographic retrieval and courseware materials, in addition to the main channel of access to information of free social resources, such as Baidu, Google and other search engines. Many students wrote the papers with a whole bunch of patchworks of these free information resource. The authenticity, scientific and applicability of these information resources are questionable. As a result, these studies in turn adversely affecting the quality of education.

In order to study the causes of this phenomenon, the authors selected 62 institutions of higher education for case study according to geographical distribution. Within the 62 institutions, there are 23 colleges and universities directly under the Ministry of Education, and 39 universities from the local area. These institutions of higher education include all provincial, autonomous regions and municipal levels excluding Taiwan Province, Hong Kong and Macao areas. There are 17 comprehensive colleges, 13 Engineering colleges as well as 6 teacher colleges, 6 financial, and 6 medical colleges respectively. There are 3 Politics and Law Schools and 3 schools of foreign languages. There are 2 sports andlor art schools and 4 agriculture, forestry, animal husbandry colleges. This case study comprises of a strong representation.

Searching in the library websites of above institutions of higher education, the authors found that the current library information services are mostly functioned to satisfied the need of "knowledge points" (i.e. a particular book or article). Undergraduate students have two main difficulties when using these facilities to retrieve information:

The problem of low academic achievement resulted in poor understanding of the information retrieved and might be getting irrelevant information as targeted.

Insufficient time to process the information retrieved to fit into the special subject they focus on, in that unlike graduate students, undergrads have to face heavy duty studies in the semester and there is too little time they could afford to spend on individual courses.

From the case study, most of the libraries (100\% of the universities directly under the Ministry of Education, and $97.6 \%$ of the local undergraduate institutions) have established their collection of bibliographic database to provide a personalized service network for all staffs and students. This includes bibliographic index information, personal loan history, ordering books, renewing books and so on. However, you can hardly see the second or third indexing documents to facilitate the development of undergraduate students.

The authors have extracted representative information service items (be included in over eighty percent of the sample websites) from the interested 62 university libraries web site for case study. Then, we have conducted a questionnaire survey among 189 students in grades 2, 3 and 4 of our university. The findings are shown in Table 1.

"Collection Search (bibliographic index)" is seen as the most frequently used item. $78.3 \%$ of students in this survey admitted that these services are most frequently used. The use of other services is of relatively low frequency. There are some services that have "never used", the proportion of it nearly among to $38 \%$.

Table 1.

Questionnaire results.

\begin{tabular}{|c|c|c|}
\hline \multirow{2}{*}{ Items } & \multicolumn{2}{|c|}{ Results } \\
\hline & Frequently used & Never used \\
\hline Collection Search & $148(78.3 \%)$ & $9(4.8 \%)$ \\
\hline Renew Books & $84(44.7 \%)$ & $38(20.2 \%)$ \\
\hline My Library History & $69(36.5 \%)$ & $47(24.9 \%)$ \\
\hline Category Navigation & $68(36 \%)$ & $32(16.9 \%)$ \\
\hline My Search History & $45(23.8 \%)$ & $60(31.8 \%)$ \\
\hline My Needs & $40(21.3 \%)$ & 62(33\%) \\
\hline Reservation Books & $35(18.5 \%)$ & $61(32.5 \%)$ \\
\hline Recommended Books & $35(18.5 \%)$ & 62(32.8\%) \\
\hline Lending Ranking & $33(17.5 \%)$ & $59(31.2 \%)$ \\
\hline New Books & $30(16 \%)$ & $67(35.6 \%)$ \\
\hline Readers Recommend & $27(14.4 \%)$ & $71(37.8 \%)$ \\
\hline Book Review & $26(13.8 \%)$ & $70(37.2)$ \\
\hline My Collection & $19(10.1 \%)$ & $66(35.1 \%)$ \\
\hline
\end{tabular}


The findings of this questionnaire study also show that students are more interested in the need of "knowledge-line". The so-called "knowledge-line" refers to a special topic or the knowledge of a special category ${ }^{[17]}$. For instance, the knowledge in regards to the concept of "financial crisis", or the scientific and academic knowledge in regards to the nationwide competition of university students' masterpiece of designs etc.. Over $80 \%$ of the students in this survey called for an increase in such navigation services.

These factors show that such a huge digital resources platform to facilitate universities and the society has not yet achieve maximum benefit for the huge information receiver groups in the universities. The main problem is not related to students who are not familiar with the principle and operation of the system, but due to the lack of information navigation aids.

This must bring to the attention of all to be fully aware of that, for most undergraduate students, it is a guiding process to lead them to grow from relying on classroom teaching materials learning to advance through interdisciplinary thematic literature to obtain the required self-knowledge.

It is the major task for higher education to improve the process of such guidance. University libraries should focus on the integration of resources to provide efficient and convenient ways for undergraduate student groups, in order to improve and enhance the students' information literacy in a gradual and orderly manner.

\section{Some Porpasals to Improve the Task of Information Services}

Now that we are already in possession of high-quality academic subject databases, we could be able to put them into great effect as long as we know how to utilize these resources to educate our students. The authors believe that in order to achieve this goal, we must first and foremost full fill the tasks as follows:

In reference to the way of organizing and coordinating the CALIS and CADLIS projects, we will systematically unify the digital resources for the benefit of students and at the same time emphasize on individual responsibility. The universities and colleges bearing the responsibility for building scientific subject matter databases must choose a subset of the material in the databases for students specialized in the field, and provides an overview of the topic, in the mean time open to other institution for resources sharing purposes.

Perfect the principle of differentiated services in that setting up the school's digital resources portal web design to a different window and thus, setting up a navigation interface for different groups with unique classifications and needs. We expect that this would enable the readers to reach a fast and accurate access to relevant resources according to their needs.

Enhance the collaboration between library and classroom teaching, establish and update digital resources navigation for undergraduate specialties according to the progress of the local economic zone.

Embed the teaching of information literacy into professional courses for graduating students. When it comes to the stage of graduate thesis or designs they could be able to use the system of special databases directly to complete their trainings in such respect.

\section{Conclusion}

In summary, the current university library information services have not yet been able to meet the requirements of undergraduate educational reform, and years of development on digital resources with carrying out in large-scale has not produced desired results at undergraduate education. This is a problem that is worth to take seriously. Further improvement of the library information service work is important for implementation of PETOE project.

\section{REFERENCES}

Lin Jian, "The development of general standards for 'A Plan for Educating and Training Outstanding Engineers',” Research in Higher Education of Engineering, 2010, No.4, pp.21-29

Lin Jian, "Reformation of outstanding engineers'training oriented curriculum system and course content," Research in Higher Education of Engineering, 2011, No.5, pp.1-9

Chen Li, "Reform of literature retrieval course in colleges and universities based on information literacy education," Chin J Med Libr Inf Sci, vol. 20, No.5, pp.45-46,60

Kan Xiaoliang, "On the university students'information quality and electronic resource utilization,"Library Work in Colleges and Universities, vol.31, No.142, pp.68-70

Huang Chen, “China Academic Digital Library:plan and practice," Journal of Library Science in China, vol.37, No.194, pp.38-42

Xiao Xiaobo, Yan Xiaodi, Shao Jing, Zhang Huijun, "The CALIS subject online resource navigation database and suggestions for phase-III,” Journal of Intelligence, vol.3o, No.8, pp.134-137

Wu Zhipan, “CADLIS way of knowledge innovation,” Journal of Academic Libraries, 2006, No.5, pp.2-6

Hu Naizhi, "China Higher Education Digital Library (CADLIS) project start-cum-achievement report of the session," Library Development, 2005, No.1, pp.114

Li Xiaoming, "From CALIS to CADLIS_ — on the Initiation of China Academic Digital Libraries and Information System Project,” Journal of Academic Libraries, 2004, No.5, pp.3-4, 10

Chen Haiyan, "Practice on the construction of characteristic database in university libraries,”Academic Library and Information Tribune, vol.8, No.4, pp.22-24

$\mathrm{Hu}$ Gefu, "On the construction of characteristic database in university libraries,”Library \& Information Service of Zhejiang Universities \& Colleges, 2009, No.6, pp.23-26,54

Liu Yuanyuan and Liu sha,'The practice in and reflection on the characteristic construction of university libraries,"Journal of Academic Library and Information Science,vol.29, No.3, pp.42-45,72

Yao Xiaoxia, Xiao Long, and Chen Ling,’Ten years development of CALIS in 21 century,”Library Work in Colleges and Universities, vol.30, No.140, pp.3-6

Ge Hang, "Function and position of libraries in information delivery system,”Knowledge of Library and Information Science, 2003, No.3, pp.11-13 


\section{DAI ET AL.}

Lu Xia, "Research on choosing network resources in CALIS key discipline navigation database construction,” Academic Library and Information Tribune, vol.9, No.3, pp.13-15, 46

Wu Xuemei, "CALIS of the university library ancient bibliographic database construction,” Art Education, 2011, No.2, pp.159-160

Wang ZiZhou, Library Tutorial, Wuhan University Press, 2003, pp.175-187 